\title{
Energy expenditure of extreme competitive mountaineering skiing
}

\author{
Caroline Praz $\cdot$ Bertrand Léger $\cdot$ Bengt Kayser
}

Received: 25 April 2014 / Accepted: 13 June 2014 / Published online: 5 July 2014

(C) Springer-Verlag Berlin Heidelberg 2014

\begin{abstract}
Purpose Multi-hour ski mountaineering energy balance may be negative and intake below recommendations.

Methods Athletes on the 'Patrouille des Glaciers' racecourses (17 on course Z, $27 \mathrm{~km},+2,113 \mathrm{~m} ; 11$ on course $\mathrm{A}, 26 \mathrm{~km},+1,881 \mathrm{~m})$ volunteered. Pre-race measurements included body mass, stature, $V \mathrm{O}_{2 \max }$, and heart rate $(\mathrm{HR})$ vs $\mathrm{VO}_{2}$ at simulated altitude; race measurements $\mathrm{HR}$, altitude, incline, location, and food and drink intake (A). Energy expenditure (EE) was calculated from altitude corrected $\mathrm{HR}$ derived $\mathrm{VO}_{2}$.

Results Race time was 5 h 7 min \pm 44 min (mean $\pm \mathrm{SD}$, $\mathrm{Z})$ and $5 \mathrm{~h} 51 \mathrm{~min} \pm 53 \mathrm{~min}$ (A). Subjects spent $19.2 \pm 3.2 \mathrm{MJ}(\mathrm{Z})$, respectively, 22.6 $\pm 2.9 \mathrm{MJ}(\mathrm{A})$ during the race. Energy deficit was $-15.5 \pm 3.9 \mathrm{MJ}(\mathrm{A})$; intake covered $20 \pm 7 \%$ (A). Overall energy cost of locomotion (EC) was $9.9 \pm 1.3 \mathrm{~J} \mathrm{~m}^{-1} \mathrm{~kg}^{-1}(\mathrm{Z}), 8.0 \pm 1.0 \mathrm{~J} \mathrm{~m}^{-1} \mathrm{~kg}^{-1}$ (A). Uphill EC was $11.7 \pm 1 \mathrm{~J} \mathrm{~m}^{-1} \mathrm{~kg}^{-1}$ (Z, $13 \%$ slope) and $15.7 \pm 2.3 \mathrm{~J} \mathrm{~m}^{-1} \mathrm{~kg}^{-1}$ (A, $19 \%$ slope). Race A subjects lost $-1.5 \pm 1.1 \mathrm{~kg}$, indicating near euhydration. Age, body mass, gear mass, $V \mathrm{O}_{2 \max }$ and $\mathrm{EC}$ were significantly correlated with performance; energy deficit was not.
\end{abstract}

Communicated by Michael Lindinger.

C. Praz · B. Kayser $(\bowtie)$

Institute of Sports Sciences and Department of Physiology, Faculty of Biology and Medicine, University of Lausanne, Géopolis, Campus Dorigny, 1015 Lausanne, Switzerland e-mail: bengt.kayser@unil.ch

C. Praz $\cdot$ B. Léger

Institute for Research in Rehabilitation, SuvaCare Rehabilitation

Clinic, Sion, Switzerland
Conclusions Energy expenditure and energy deficit of a multi-hour ski mountaineering race are very high and energy intake is below recommendations.

Keywords Endurance $\cdot$ Energy balance $\cdot$ Altitude $\cdot$ Skiing

$\begin{array}{ll}\text { Abbreviations } \\ \text { ACSM } & \text { American College of Sport Medicine } \\ \mathrm{EC} & \text { Energy cost } \\ \mathrm{EE} & \text { Energy expenditure } \\ \mathrm{HR} & \text { Heart rate } \\ \mathrm{HR}_{\text {max }} & \text { Maximal heart rate } \\ \mathrm{HR}_{\text {mod }} & \text { Modified heart rate } \\ \mathrm{HR}_{\mathrm{res}} & \text { Heart rate reserve } \\ \mathrm{MET} & \text { Metabolic equivalent of task } \\ \mathrm{m}_{\mathrm{vert}} & \text { Vertical meter } \\ s_{1} & \text { Speed 1 } \\ s_{2} & \text { Speed } 2 \\ s_{3} & \text { Speed } 3 \\ \mathrm{SD} & \text { Standard deviation } \\ V \mathrm{O}_{2} & \text { Oxygen consumption } \\ V \mathrm{O}_{2 \mathrm{max}} & \text { Maximal oxygen consumption } \\ \mathrm{vt}_{2} & \text { Ventilatory threshold } 2\end{array}$

\section{Introduction}

Ski mountaineering for leisure and competition has become popular in alpine countries over the past decades. It consists of ascending snow-covered slopes on skis with special bindings that allow pivoting at the toe, letting the heel free when climbing, and fixing it when skiing down hill. For climbing, adhesive nylon or mohair skins are attached under the skis, preventing sliding backward. 
There are several types of ski mountaineering races: individual, team (team members must stay together), relay (team members relay each other), vertical (uphill only), sprint and long distance races. The main differences are the total vertical and horizontal distances covered and the distribution of downhill and uphill sections. Team events alternate several steep ascents with downhill sections (ISMF 2012-2013, http://www.ismf-ski.org). During transitions skins are quickly removed or applied, and the bindings changed to the uphill or downhill position, respectively. Downhill sections are mostly 'off-piste', where the snow is not groomed, while uphill sections are usually prepared with two parallel trails to allow overtaking. In addition to uphill and downhill sections on skis, there can be running, walking and steep climbing sections, with skis fastened on the backpack, and flat sections where the athlete adopts a cross-country skate skiing-like movement. Team races are often several hours long. Most of the time, two or three participants make up a team. Athletes must carry most of their liquid and solid food on them, as there generally are few if any food and drink stations along the racetrack.

Few studies have been carried out on ski mountaineering. Tosi et al. (2009) estimated the energy cost (EC) of ski mountaineering on packed snow (slope $21 \%$ ) and described EC variations with speed and ankle load. They also reported that the effect of ankle load on EC is negligible for recreational skiers but relevant for elite skiers, explaining the on-going quest for lighter ski boots and skis in competition. In a second study they measured EC on a motorized treadmill using roller skis (Tosi et al. 2010) and showed that locomotor efficiency depends on speed, with the skiers self-selecting a speed minimizing EC. Duc et al. (2011) studied the physiological demand during an actual ski mountaineering race. They chose an individual race, shorter than most team races, with a series of uphill and downhill sections (mean duration $1 \mathrm{~h} 40 \mathrm{~min} \pm 11 \mathrm{~min}$ ). They showed that such type of ski mountaineering race is very strenuous, due to the large fraction of time spent around the respiratory compensation threshold. Diaz et al. (2010) reported a negative energy balance during a 2-day ski mountaineering competition accompanied by signs of increased oxidative stress, but did not actually measure energy expenditure.

To infer more about long duration ski mountaineering races we must refer to events of similar duration in other endurance sports like ultra-marathon and trail running, cycling or cross-country skiing. For team ski-mountaineering races, like for other types of endurance sports of long duration, EE is expected to be very high and energy intake low. This would imply a large energy deficit and the guidelines of the ACSM (Rodriguez et al. 2009) for endurance sports, $0.7 \mathrm{~g}$ carbohydrates $\mathrm{kg}^{-1} \mathrm{~h}^{-1}$, might not be met (Diaz et al. 2010) although carbohydrate ingestion during exercise is known to improve performance during endurance events (Jeukendrup 2011). In endurance sports with races lasting several hours there is also risk for excessive dehydration. The guidelines of the ACSM indicate that endurance athletes should limit body mass losses from sweating to $2-3 \%$ of body mass (Rodriguez et al. 2009; Jeukendrup 2011). Kruseman et al. (2005) found a weight loss of $4.5 \pm 1.5 \mathrm{~kg}$ in runners after participating in a mountain marathon lasting $7 \mathrm{~h}$, mostly from loss of water. We expected that a multi-hour ski mountaineering race would also lead to significant dehydration.

In order to better describe the physiological demand of ski-mountaineering and predictors of race results we therefore set out to measure EC and EE in participants to a competitive extreme ski mountaineering race in the Swiss Alps, 'La Patrouille des Glaciers', combining laboratory indirect calorimetry test results with HR monitoring during the race. We tested the following hypotheses: (1) athletes' EE is very high and only partly covered by energy intake; (2) athletes develop significant dehydration ( $>3 \%$ body mass); (3) race performance is function of age (Lara et al. 2014), low altitude aerobic capacity, fractional use of HR reserve $\left(\mathrm{HR}_{\mathrm{res}}\right)$, body and racing gear weight (Tosi et al. 2009) and technical competences for uphill and down-hill skiing [linked to EC (Tartaruga et al. 2013)].

\section{Methods}

The protocol of the study was approved by the Valais research ethics committee (CCVEM 033/11). Each participant gave informed written consent prior to participate to the study.

\section{The race}

The study was conducted during the 'Patrouille des Glaciers' (http://www.pdg.ch) held on 25, 26, 27 and 28 April 2012. The 'Patrouille des Glaciers' is the most famous and popular ski mountaineering race in Switzerland with 1,450 selected teams of three skiers each that must stay grouped at all times. The worlds best ski mountaineering athletes participate in the race. The race consists of different types of locomotion: running, walking, and steep climbing on foot, ascent on skis with adhesive skins applied, alpine skiing style descents, and cross-country skating-like skiing.

There are two official race routes, one from Zermatt to Verbier (race Z; distance $53 \mathrm{~km}$; altitude differences $+3,994$ and $-4,090 \mathrm{~m}$; maximal altitude 3,650 m) and one from Arolla to Verbier (race A, distance $26 \mathrm{~km}$; altitude differences $+1,881$ and $-2,341 \mathrm{~m}$; maximal altitude $3,160 \mathrm{~m}$ ) (Fig. 1) and two races on separate days for each race route. In 2012 due to high avalanche danger one start of each race 


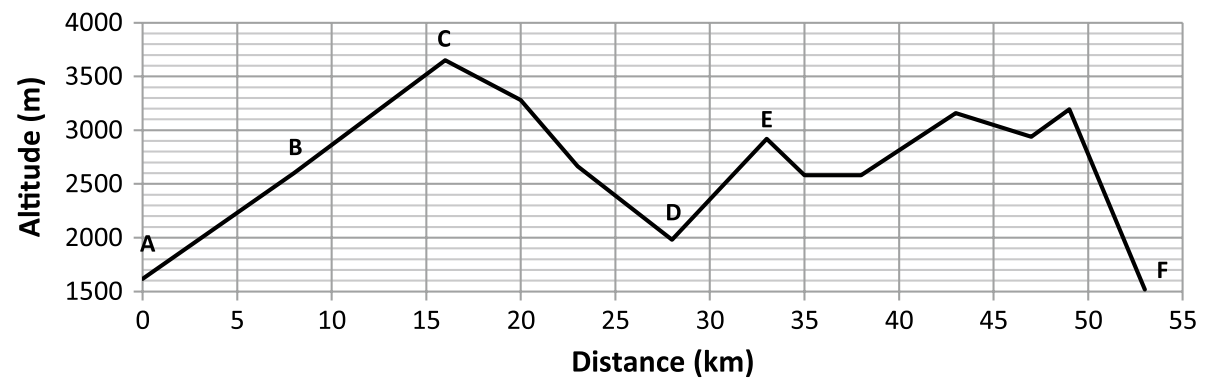

Fig. 1 Racetrack of the Patrouille des Glaciers: A start of race Z, B start of the separately analysed ski mountaineering uphill section of race Z, $C$ finish of the separately analysed ski mountaineering uphill section of race $\mathrm{Z}, D$ finish of race $\mathrm{Z}$ after racetrack modification, start

route was cancelled. Half the participants of the race A could race normally and half the participants of the race $\mathrm{Z}$ could race but were stopped after $27 \mathrm{~km}$ (instead of 53) and 2,113 $\mathrm{m}$ ascent and 1,749 $\mathrm{m}$ descent. This change of racetrack $\mathrm{Z}$ was not known at the start of the race; participants were only informed when stopped in Arolla.

The modified route of the race $\mathrm{Z}$ consisted of a $16 \mathrm{~km}$ uphill section followed by an $11 \mathrm{~km}$ downhill section. The first part of the uphill section was covered walking or running with the skis attached to the backpack. Then the participants put their skis with adhesive skins on and walked up on skis. We analysed separately this uphill section where the athletes used their skis mounted with skins (distance $8 \mathrm{~km}$, mean slope $13 \%$ ). The route of the race A began with an ascent section (distance $5 \mathrm{~km}$, mean slope $19 \%$ ) that we also analysed separately. Then there were an uphill section, a flat section, an uphill section and the final downhill. The athletes walked, ran, climbed on skis with skins applied, and skied downhill during the race.

The weather conditions at the start sites were: minimal temperature: $3{ }^{\circ} \mathrm{C}$ for the first race day and $10^{\circ}$ for the second race day, maximal temperature: 14 and $19^{\circ} \mathrm{C}$; mean air humidity was 37 and $20 \%$ and maximal wind speed 35 and $50 \mathrm{~km} \mathrm{~h}^{-1}$, respectively, while at $3,500 \mathrm{~m}$, for the two race days, minimal temperature, maximal temperature, air humidity and maximal wind speed were, respectively: -3 and $0{ }^{\circ} \mathrm{C},-8$ and $-6{ }^{\circ} \mathrm{C}, 66$ and $61 \%$ and 70 and $59 \mathrm{~km} \mathrm{~h}^{-1}$.

\section{Subjects}

Seventy subjects were recruited (40 for the race $\mathrm{Z}$ and 30 for the race A); 28 subjects could be taken into account due to the cancellation of several races. They were all healthy and trained skiers. 17 (14 men, 3 women) took part in race $\mathrm{Z}$ and 11 (11 men) in race $\mathrm{A}$. Their mean $\pm \mathrm{SD}$ age, height, body mass, body fat percentage and maximal oxygen consumption $\left(V \mathrm{O}_{2 \max }\right)$ were, respectively, $41 \pm 6$ years, of race A and start of the separately analysed ski mountaineering uphill section of race A, $E$ finish of the separately analysed ski mountaineering uphill section of race $\mathrm{A}$ and $F$ scheduled finish of race $\mathrm{Z}$ and finish of race $A$

$177 \pm 6 \mathrm{~cm}, 69 \pm 9 \mathrm{~kg}, 12 \pm 5 \%, 60 \pm 5 \mathrm{ml} \mathrm{kg}^{-1} \min ^{-1}$ for the race $\mathrm{Z}$ subjects and $30 \pm 10$ years, $178 \pm 7 \mathrm{~cm}$, $74 \pm 8 \mathrm{~kg}, 15 \pm 5 \%, 54 \pm 5 \mathrm{ml} \mathrm{kg}^{-1} \mathrm{~min}^{-1}$ for the race A subjects. There were no significant differences between groups.

\section{Research design}

The experimental protocol consisted of two visits to the laboratory prior to the race and measurements on race day. The aim of the first laboratory visit was to characterize the participants [anthropometry and aerobic fitness level $\left.\left(V \mathrm{O}_{2 \max }\right)\right]$. The second visit allowed creating individual HR-altitude- $V \mathrm{O}_{2}$ equations, which were then used to estimate $\mathrm{EE}$ from $\mathrm{HR}$ and altitude measured during the race.

Anthropometry and maximal test

Between 2 and 3 months prior to the race, anthropometric features, body composition, $V \mathrm{O}_{2 \max }$ and maximal $\mathrm{HR}$ $\left(\mathrm{HR}_{\max }\right)$ were determined. Body fat percentage was measured by air displacement plethysmography (BodPod, Cosmed, Italy). The subjects performed a maximal running test on a motorized treadmill (HP Cosmos Pulsar, Germany) to determine $V \mathrm{O}_{2 \max }$ and $\mathrm{HR}_{\text {max }}$. Running was chosen because maximum exercise testing while walking/running uphill on skis with skins applied (uphill ski mountaineering) in the laboratory was technically too difficult for most athletes. Running on a treadmill was assumed to involve a sufficiently similar muscle mass volume as ski mountaineering and most athletes used running for base training. After warm-up ( $3 \mathrm{~min}$ at $5.4 \mathrm{~km} \mathrm{~h}^{-1}$ ), speed was set at $7.2 \mathrm{~km} \mathrm{~h}^{-1}$ and increased by $1.8 \mathrm{~km} \mathrm{~h}^{-1}$ every 3 min without breaks between stages up to voluntary exhaustion under strong verbal encouragement. The inclination of the treadmill was $0 \%$. Gas exchange and breathing variables were measured breath-by-breath throughout with a metabolic measurement system (Metalyser, Cortex, Germany) and HR with a portable HR monitor 
(Suunto t6d, Finland). The data obtained during the last $30 \mathrm{~s}$ of each step were considered for the analysis. The metabolic system was calibrated prior to each experimental session with a 31 syringe and gases of known composition. The HR results were analysed according to five exercise intensity zones to describe the intensity profile during the race: $<60 \%$ of the $\mathrm{HR}_{\text {res }}$, between 60 and $70 \% \mathrm{HR}_{\text {res }}$, between 70 and $80 \% \mathrm{HR}_{\text {res }}$, between 80 and $90 \% \mathrm{HR}_{\mathrm{res}}$ and $>90 \% \mathrm{HR}_{\text {res, }}$, with $\mathrm{HR}_{\text {res }}$ defined as the difference between resting $\mathrm{HR}$ and $\mathrm{HR}_{\text {max }}$ (Achten and Jeukendrup 2003; Gatterer et al. 2013; Haddad et al. 2014; Vernillo et al. 2012). Resting HR was measured with the athlete standing quietly on the treadmill before the start of the $V \mathrm{O}_{2 \max }$ test. As a second means for the quantification of exercise intensity we determined the ventilatory threshold $2\left(\mathrm{vt}_{2}\right)$ with the V-slope method (Wasserman and McIlroy 1964).

Individual altitude corrected $\mathrm{HR}-\mathrm{VO}_{2}$ relationships

Between 2 and 4 weeks before the race, each subject performed a trial by ascending on skis on a motorized treadmill with a slope set at $19 \%$ (Cosmed Venus, Italy). There were 12 stages at different speeds and simulated altitudes. The subjects were equipped with their own racing gear including clothes, skis, skins, boots, poles, helmet, backpack, avalanche probe, snow shovel, avalanche transceiver, head lamp, food, drink, etc. (11.4 $\pm 2.6 \mathrm{~kg})$. The purpose was to obtain individual altitude corrected $\mathrm{HR}-V \mathrm{O}_{2}$ relationships for each participant in order to interpret the HRs recorded during the race as metabolic rates. Since altitude exposure during the race is acute we exposed the subjects to acute simulated altitude, having the subjects breathe $\mathrm{N}_{2}$ enriched air through a mask from a mixing bag continuously monitored for partial pressure of oxygen, equivalent to the desired altitude (AltiTrainer, SMTec, Switzerland). At each altitude $(500,2,500,3,500 \mathrm{~m})$ the participants performed four 3 min stages: rest, speed $1\left(s_{1}\right)$, speed $2\left(s_{2}\right.$, estimated race pace) and speed $3\left(s_{3}\right) . S_{2}$ was self-selected by each subject $s_{1}$ was $0.5 \mathrm{~km} \mathrm{~h}^{-1}$ slower than $s_{2}$ and $s_{3}$ $0.5 \mathrm{~km} \mathrm{~h}^{-1}$ faster than $s_{2}$. The total duration was 36 min for the 12 stages. Between $s_{1}, s_{2}$ and $s_{3}$ there was no break and the order of the stages was always the same for all the subjects. $V \mathrm{O}_{2}$ and $\mathrm{HR}$ were measured and recorded in the same way as for the maximal test except that a portable indirect calorimetry system (Metamax, Cortex, Germany) was used. These measurements allowed us to draw up relationships with individual coefficients between $\mathrm{HR}$, altitude and $\mathrm{VO}_{2}$ for each subject.

Since HR varied non-linearly with speed and simulated altitude, the data were fitted with exponential functions (1) in order to derive correction factors, which allowed calculating an equivalent low altitude $\mathrm{HR}\left(\mathrm{HR}_{\mathrm{mod}}\right)$ from $\mathrm{HR}$ measured at any altitude during the race (Richalet 2012):
$\mathrm{HR}_{\text {mod }}=\mathrm{HR}-a^{(- \text {altitude } / b)}+y_{0}$

with $y_{0}$ the $y$ axis intercept, i.e., the HR found at that given speed at $500 \mathrm{~m}$ and $a$ and $b$ determined individually for each subject.

Then $\mathrm{HR}_{\text {mod }}$ was then linked to a $\mathrm{VO}_{2}(2)$.

$V \mathrm{O}_{2}=c \cdot \mathrm{HR}_{\mathrm{mod}}+d$

with $c$ and $d$ determined individually for each subject (Keytel et al. 2005; Wicks et al. 2011).

In addition, body fat percentage and mass were measured again on this day to have values close to the race day.

Day -4 to race day measurements

From day 4 before the race till pre-race meal, the participants noted every food item or drink they consumed. On race day, 1 to $2 \mathrm{~h}$ prior to the departure, after voiding, the subjects were weighed with a scale (precision $100 \mathrm{~g}$, Mio Star Body Balance, Melectronic, Migros, Switzerland), once in underwear only and once carrying complete race equipment, skis, boots and poles included (12.9 \pm 3.0 , $1.5 \mathrm{~kg}$ more than during the treadmill test).

Race HR was recorded beat-by-beat (t6d or Memory Belt, Suunto, Finland). For each team altitude was also continuously measured (t6d, Suunto, Finland). Each subject collected the wrappings of all food items consumed during the race. Any liquid or food intake on the way other than that carried was noted.

The 11 subjects of six teams that reached their scheduled finish (race A) were weighed again with and without racing gear immediately upon arrival before they ate or drank anything. One athlete gave up because of injury, one was disqualified because his team was too slow and two could not be taken into account because their watch did not record HR. The 15 others could not race because their start was cancelled. Upon arrival any food or drink items consumed during the race from other sources than the supplies carried were recorded by checking and discussing the notes of the participants and crosschecking the answers with the other team members. The subjects of the race $\mathrm{Z}$ were not taken into account for weight measurement and food intake because they did not reach the scheduled finish line and could not be weighted again and asked about eating and drinking.

Individual calibration equations relating $\mathrm{HR}$ and altitude to $V \mathrm{O}_{2}$ obtained during simulated uphill skiing on the treadmill were used to calculate $V \mathrm{O}_{2}$ at any time point during the race (Achten and Jeukendrup 2003). We estimated EE using a conversion factor of $20 \mathrm{~kJ} \mathrm{~L} \mathrm{O}_{2}^{-1}$ assuming an average metabolic respiratory quotient of 0.8 representing a mixed energy substrate including use of fat mass energy reserves. EC $\left(\mathrm{J} \mathrm{m}^{-1} \mathrm{~kg}^{-1}\right)$ was calculated with the estimated EE (J) per mass unit (body mass+equipment 
mass) (kg) divided by the absolute distance covered (m). EC per vertical meter $\left(m_{\text {vert }}\right)$ was measured with the estimated EE (J) per mass unit (body mass+equipment mass) $(\mathrm{kg})$ divided by the altitude difference $(\mathrm{m})$. We estimated metabolic equivalent of task (MET), a measure expressing the energy cost of physical activities in multiples of $4.184 \mathrm{~kJ} \mathrm{~kg}^{-1} \mathrm{~h}^{-1}$. The energy intake during the race was calculated from the nutritive values indicated on the wrappings of the consumed food items (bars, gels, etc.) and using standard food tables. Liquid intake was calculated as the watery part of all ingested food and drink.

Dehydration status was estimated according to the guidelines of ACSM that indicate that body mass losses from sweating should be limited to $2-3 \%$ of body mass (Rodriguez et al. 2009; Jeukendrup 2011).

\section{Statistical analysis}

For each group mean and standard deviation (SD) values were calculated for each variable. Linear regressions were performed to verify the association between each variable and race performance (time). To assess the relative importance of each variable a multiple linear regression was then performed including those variables that were significantly associated with performance in individual linear regressions. Differences were considered significant at an alpha level of 0.05 or smaller.

\section{Results}

Race Z

Absolute best time of the $\mathrm{Z}$ race was $2 \mathrm{~h} 55 \mathrm{~min}$. For the experimental subjects who participated in race $\mathrm{Z}$ mean race time was $5 \mathrm{~h} 7 \mathrm{~min} \pm 44 \min (175 \pm 25 \%$ of the best time). Best female time was $3 \mathrm{~h} 31 \mathrm{~min}$ and our female subjects (1 patrol) took $4 \mathrm{~h} 9 \min (118 \%)$. The subjects spent $76 \pm 1 \%$ of race time going uphill and $24 \pm 1 \%$ downhill. Mean HR was $156 \pm 7 \mathrm{bpm}$, i.e., $75 \pm 7 \%$ of $\mathrm{HR}_{\text {res }}$. Going uphill $\mathrm{HR}$ was $76 \pm 7 \%$ of $\mathrm{HR}_{\text {res. }}$. Figure 2 shows the average $( \pm \mathrm{SD})$ distribution of time spent in the five intensity zones. The athletes spend $17 \pm 23 \%$ of the total time above $\mathrm{vt}_{2}$. The mean total EE was $19.2 \pm 3.2 \mathrm{MJ}\left(3.4 \pm 5 \mathrm{MJ} \mathrm{h}^{-1}\right)$. The EC (EE/distance) for the whole race was $9.3 \pm 1.2 \mathrm{~J} \mathrm{~kg}^{-1} \mathrm{~m}^{-1}$ and the EC for the $8 \mathrm{~km}$ long $13 \%$ uphill section was $11.7 \pm 1.7 \mathrm{~J} \mathrm{~kg}^{-1} \mathrm{~m}^{-1}$ or $89.4 \pm 12.6 \mathrm{~J} \mathrm{~kg}^{-1} \mathrm{~m}_{\text {vert }}^{-1}$, taking into account the $11.6 \pm 2.4 \mathrm{~kg}$ racing gear. The climbing speed for this section was $584 \pm 76 \mathrm{~m}_{\mathrm{vert}} \mathrm{h}^{-1}$ and the athletes spent about $3.3 \pm 0.5 \mathrm{MJ} \mathrm{h}^{-1}$ (12 \pm 1 METs). The uphill section analysed consisted almost exclusively of ascent on skis equipped with skins, but all the types of locomotion are included in the energy values reported for the complete race.

\section{Race A}

Absolute best race time was $3 \mathrm{~h} 32 \mathrm{~min}$. The mean race time of the study subjects in race A was $5 \mathrm{~h} 51 \mathrm{~min} \pm 53 \mathrm{~min}$ (166 $\pm 25 \%$ of best time). Mean HR was $153 \pm 8$ bpm, i.e., $71 \pm 4 \%$ of $\mathrm{HR}_{\text {res. }}$. During the uphill section HR was $82 \pm 5 \%$ of $\mathrm{HR}_{\mathrm{res}}$. The average $( \pm \mathrm{SD})$ distribution of time spent in the five intensity zones is shown in Fig. 2. The athletes spend $13 \pm 20 \%$ of the total time above $\mathrm{vt}_{2}$. The mean total EE was $22.6 \pm 2.9 \mathrm{MJ}\left(3.5 \pm 0.4 \mathrm{MJ} \mathrm{h}^{-1}\right)$. The EC for the whole race was $8.0 \pm 1.0 \mathrm{~J} \mathrm{~kg}^{-1} \mathrm{~m}^{-1}$ and the EC for the $5 \mathrm{~km}$ and $19 \%$ uphill section was $15.7 \pm 2.3 \mathrm{~J} \mathrm{~kg}^{-1} \mathrm{~m}^{-1}$ or $86.5 \pm 10.0 \mathrm{~J} \mathrm{~kg}^{-1} \mathrm{~m}_{\text {vert }}^{-1}$, taking into account the $14.8 \pm 2.7 \mathrm{~kg}$ equipment. The climbing speed for this section was $632 \pm 104 \mathrm{~m}_{\text {vert }} \mathrm{h}^{-1}$ and the athletes spent $3.8 \pm 0.5 \mathrm{MJ} \mathrm{h}^{-1}(13 \pm 2$ METs $)$. Participants
Fig. 2 Exercise intensity fraction of race time (in $\%$ of race time) in each intensity zone for race $A$ and race $Z$ : the distribution of the intensity zones was similar for both races but the subjects of race $\mathrm{Z}$ started out expecting to complete a $53 \mathrm{~km}$ route and not only $27 \mathrm{~km}$, therefore they paced their race for a twice as long race as the race they finally did

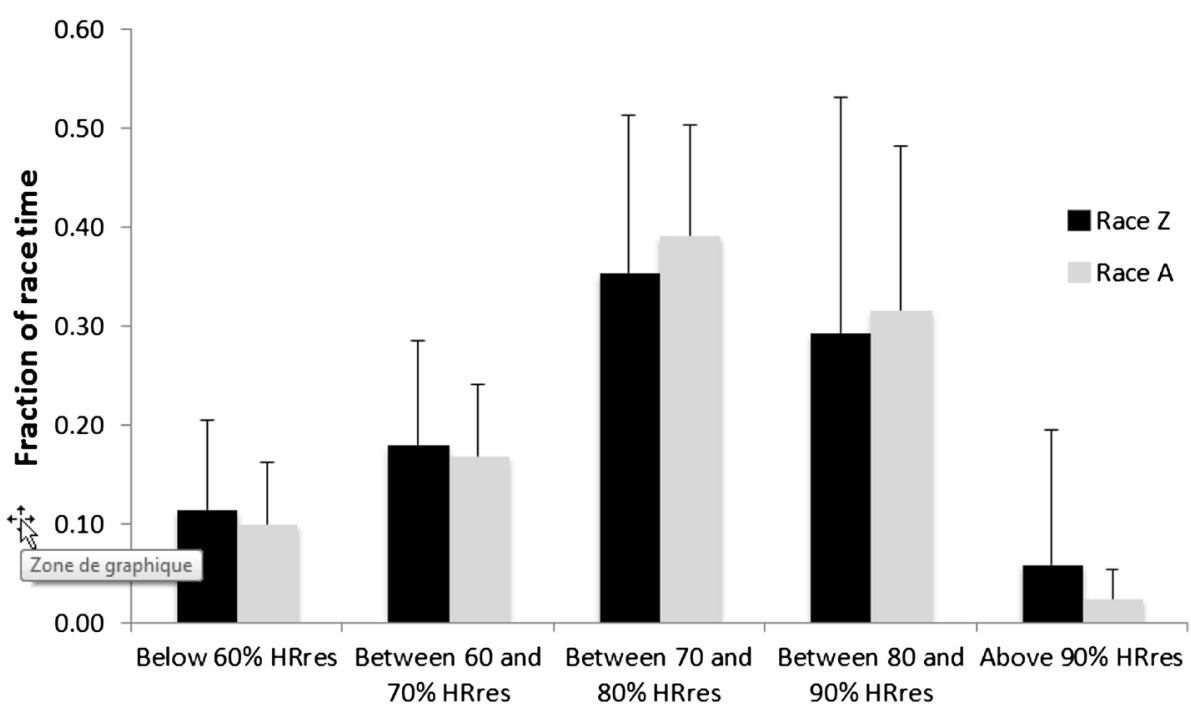




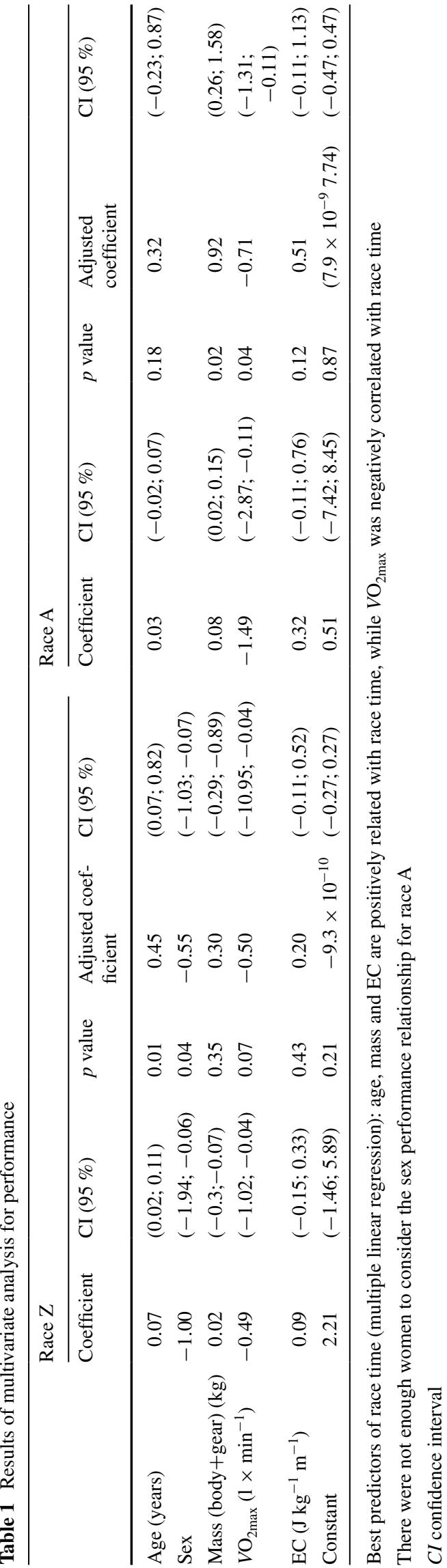

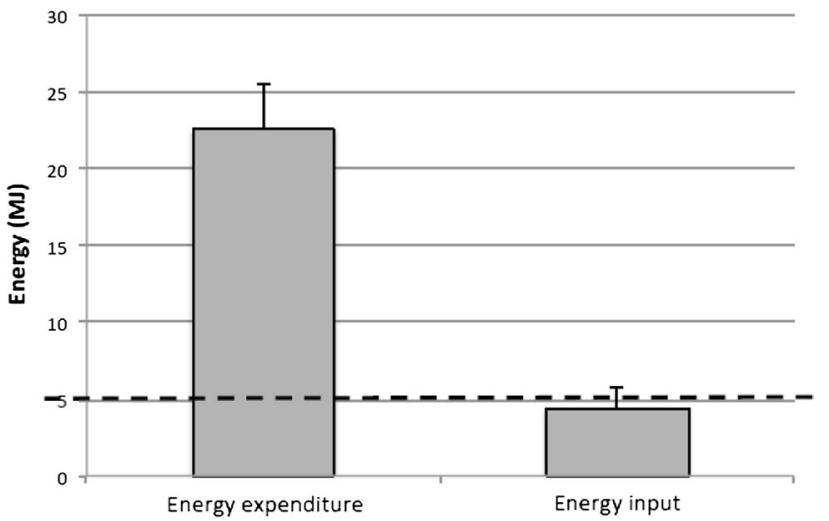

Fig. 3 Energy expenditure and energy intake comparison between energy expenditure, energy intake and recommended energy intake (dotted line) for the $26 \mathrm{~km}$ race A. The total energy intake reached $20 \pm 7 \%$ of the $\mathrm{EE}$

ate and drank during the race for a total energy intake of $4.4 \pm 1.3 \mathrm{MJ}$ reaching $20 \pm 7 \%$ of the EE (Fig. 3) and a fluid intake of $1.8 \pm 0.7 \mathrm{l}$. The mean weight loss was $1.5 \pm 1.1 \mathrm{~kg}$ ( $2 \pm 1 \%$ of body mass). The energy intake of the pre-race breakfast was 3,056 $\pm 1,059 \mathrm{~kJ}$. Total energy intake (pre-race meal+intake during the race) thus reached $35 \pm 12 \%$ of race EE. During the 4 days before the race, they ate $10.6 \pm 2.3 \mathrm{MJ} \mathrm{day}^{-1}(n=9)$.

\section{Correlates of performance}

Multivariate analysis showed positive associations between body mass, racing gear mass, body fat percentage, average $\mathrm{EC}$ for the whole race, EC of the uphill section, with race time, and a negative association between $V \mathrm{O}_{2 \max }$ with race time (Table 1).

\section{Discussion}

The main findings were that participants of an extreme competitive ski mountaineering race, 'La Patrouille des Glaciers', (1) developed an important energy deficit, which was only partly covered by energy intake en route (race A), (2) showed no significant dehydration despite 4-7 h of endurance effort at 12-13 \pm 2 METs and the need to dispose of up to $3 \mathrm{MJ}$ of heat $\mathrm{h}^{-1}$ (climbing sections), and (3) had a race performance which correlated to age, sex, body and gear mass, aerobic capacity and locomotor efficiency but not to liquid and energy intakes.

Energy expenditure

The energy requirement for a multi-hour ski mountaineering race is very high with a mean EE in our study of 
11-26 MJ for exercise durations of 5-6 h. If the race $\mathrm{Z}$ had taken place normally, the duration would have been about twice so long and the EE twice as high, or about $35 \mathrm{MJ}$. A pilot study in 2010 on six men, of which three completed the whole race $\mathrm{Z}$ yielded $43.1 \pm 0.6 \mathrm{MJ}$. In comparison, Kimber et al. (2002) showed that the EE for a triathlon ironman is $42.0 \pm 3.9 \mathrm{MJ}$ for men and $35.9 \pm 4.2 \mathrm{MJ}$ for women for durations similar to the scheduled duration of the race $\mathrm{Z}$ of our study, without the mid-race stop. Saris et al. (1989) found that cyclists who participate in the Tour de France have a mean daily EE of 25.4 MJ and reach 32.7 MJ on mountain days, again values similar to that of the modified race $\mathrm{Z}$ and of race A. Cross-country skiers expend between 13 and $15 \mathrm{MJ}$ for a $50 \mathrm{~km}$ race (Meyer et al. 2011). The environment of the latter sport is more similar to the environment of ski-mountaineering racing than cycling or triathlon, but the duration is shorter. A multi-hour ski mountaineering event therefore belongs to the category of extreme activities and can be considered as very strenuous and energy-demanding, with even higher intensities reached for races of shorter duration (Duc et al. 2011).

Calculated over $24 \mathrm{~h}$, race day energy expenditure can be estimated as $24.6 \pm 3.9 \mathrm{MJ}$ for the participants of the race $\mathrm{Z}$ and $28.9 \pm 2.9 \mathrm{MJ}$ for the participants of the race A, supposing that the athletes did not engage in significant other additional physical activity except participating to the race. This total daily expenditure was calculated by summing calculated basal metabolic rate considering sex, weight, stature and age [Black formula (Black et al. 1996)], physical activity induced energy expenditure and $10 \%$ of total energy expenditure to take into account the thermic effect of food (Black et al. 1996). The physical activity level (PAL), defined as daily energy expenditure divided by basal metabolic rate, on race day thus amounted to $2.4 \pm 0.4$ for participants doing race $\mathrm{Z}$ and $3.0 \pm 0.5$ doing race $\mathrm{A}$. The general population has a natural limit of sustainable daily energy turnover at a PAL of $2-2.5$ that can be maintained over several days (Westerterp et al. 1992). The high PAL values for non-elite athletes found for race A suggest that those subjects would probably not be able to maintain energy balance with time, as suggested also by the important energy deficit attained during the race.

The large muscle mass involved in this particular type of locomotion is a major reason why the EE is so high. Altitude also influences the EE. Since maximum aerobic capacity decreases with altitude, the absolute EE decreases, as athletes choose to exercise at similar relative intensity levels. In acclimatizing subjects basal metabolic rate was found higher compared to sea level (Meyer et al. 2011): at $4,300 \mathrm{~m}$ basal metabolic rate had increased by $10-17 \%$ compared to sea level, presumably because of increased sympathetic activity (Mawson et al. 2000). Altitude was lower for our race (between 1,520 and 3,650 m) and exposure short, but it is conceivable that basal metabolic rate was somewhat increased. Furthermore, cold exposure linked to the alpine environment in winter also increases EE (Meyer et al. 2011).

\section{Energy cost of locomotion}

In general the energy cost of locomotion (EC) is a prime determinant of performance for endurance type sports (di Prampero 1986) that can make the difference between two athletes with the same $V \mathrm{O}_{2 \max }$. The combination of a high aerobic capacity, a low EC and the ability to maintain a high fraction of aerobic capacity will allow better performance. In extreme ski mountaineering, global EC involves several types of locomotion like running, walking, ascent on skis with skins applied, alpine skiing in descent, or cross-country skating-like skiing. This implies that the overall EC is very dependent on the route of the particular race and differs between races according to the fraction of the race spent in the different types of locomotion. Most of the time is generally spent climbing uphill on skis equipped with adhesive skins applied and the bindings in
Table 2 Comparison between studies

EC in $\left(\mathrm{J} \mathrm{kg}^{-1} \mathrm{~m}^{-1}\right)$ of skimountaineering comparison between the values of the present study (race A and race Z) and the results of previous studies: EC calculated for race $\mathrm{A}$ is the highest because of the steep gradient and the heavier load carried

\begin{tabular}{lllll}
\hline & $\begin{array}{l}\text { Uphill section } \\
\text { of the race Z }\end{array}$ & $\begin{array}{l}\text { Uphill section } \\
\text { of the race A }\end{array}$ & $\begin{array}{l}\text { Tosi et al. } \\
(2009)\end{array}$ & $\begin{array}{l}\text { Uphill sections } \\
\text { (addition of 2) } \\
\text { Duc et al. (2011) }\end{array}$ \\
\hline Length (m) & 8,000 & 5,000 & 500 & 7,070 \\
Altitude difference (m) & 1,050 & 933 & 105 & 1,315 \\
Mean gradient (\%) & 13 & 19 & 21 & 18 \\
Mean duration (h) & $1.95 \pm 0.26$ & $1.51 \pm 0.23$ & $0.13 \pm 0.01$ & $1.4 \pm 0.2$ \\
Load $(\mathrm{kg})$ & $11.6 \pm 2.4$ & $14.8 \pm 2.7$ & $7 \pm 1$ & $\sim 4.5$ \\
Mean speed $\left(\mathrm{km} \mathrm{h}^{-1}\right)$ & $4.2 \pm 0.6$ & $3.4 \pm 0.6$ & $3.9 \pm 0.2$ & $4.8 \pm 0.9$ \\
Mean vertical speed $\left(\mathrm{m} \mathrm{h}^{-1}\right)$ & $584 \pm 76$ & $632 \pm 104$ & $808 \pm 48$ & $896 \pm 96$ \\
EC $\left(\mathrm{J} \mathrm{kg}^{-1} \mathrm{~m}^{-1}\right)$ & $11.7 \pm 1.7$ & $15.7 \pm 2.3$ & $10.6 \pm 0.4$ & $14.2 \pm 2.5$ \\
EC $\left(\mathrm{J} \mathrm{kg}^{-1} \mathrm{~m}_{\text {vert }}^{-1}\right)$ & $89.4 \pm 12.6$ & $86.5 \pm 10.0$ & $50.6 \pm 1.9$ & $78.9 \pm 13.9$ \\
\hline
\end{tabular}


open mode so that minimizing EC in that particular mode has an important impact on overall energy cost. The EC of the uphill sections we found can be compared with the results of other studies (Table 2). The lowest EC (Tosi et al. 2009) was described for a short section lasting only $8 \mathrm{~min}$ while that of races lasting 1-2 h (Duc et al. 2011) up to $6 \mathrm{~h}$ 45 (this study) are higher. The EC of the uphill section of race A had the highest EC $\left(15.7 \pm 2.3 \mathrm{~J} \mathrm{~kg}^{-1} \mathrm{~m}^{-1}\right)$; but the load that the athletes carried was also the heaviest for this race, and the movement is likely less efficient while carrying heavier backpacks. Effect of mass is even more important on EC per $m_{\text {vert }}$ as on EC per $m$ distance covered. The lower mean slope of the uphill section of the race $\mathrm{Z}$ thus probably also partly explains the lower EC. Our subjects were slower than the subjects of Duc et al. (2011) probably because our race was much longer. The highest speed and vertical speed were reported by Duc et al. (2011) because they studied an actual race situation that was shorter than 'La Patrouille des Glaciers'. Like for walking there likely is an optimal gradient of path regarding EC. The $13 \%$ gradient of race $\mathrm{Z}$ is the less economical of the already tested gradients and the $21 \%$ gradient of Tosi et al. (2009) the most economical. These results suggest that the most economical gradient may be close to the optimal gradient for walking (25\%) (Minetti 1995). Variations of EC of ski mountaineering with speed, slope, snow conditions (type and temperature of snow) are not known yet. The EC that we calculated is only for a definite speed, load and gradient and cannot be generalized for all ski-mountaineering races. To assess the EC of a given race it would be useful to know how the EC changes with those factors.

\section{Exercise intensity}

The distribution of HR in the intensity zones was similar for race A and Z (see Fig. 2). This was expected since the 2 routes were quite similar: $26 \mathrm{~km}$ for race A, $27 \mathrm{~km}$ for race $\mathrm{Z}$, with altitude differences of $+1,881$ and $-2,341 \mathrm{~m}$ for race $A$, and of $+2,113$ and $-1,749 \mathrm{~m}$ for race $Z$. However, the subjects of race $Z$ started out expecting to complete the originally scheduled route, $53 \mathrm{~km}$ long and double positive and negative altitude differences. The pace and intensity they chose were those they felt appropriate for a race twice as long as they finally completed. If we consider that the skiers who chose to participate in race $\mathrm{Z}$, the longer and generally considered elite race, were well trained and experienced skiers (their $V \mathrm{O}_{2 \max }$ was $60.1 \pm 7.5,10 \%$ higher as those participating in race $\mathrm{A}$ ), we may speculate that they would have kept this intensity for the second part of the race if it had taken place. On the other hand, HR may decrease with exercise duration and fatigue (Esteve-Lanao et al. 2008), so if the subjects of the race $Z$ had known from the departure that they would race for only $27 \mathrm{~km}$, their HR might have been somewhat higher because of the higher intensity of a faster pace.

In an individual and shorter ski mountaineering race, the 'Trace catalane', Duc et al. (2011) found a mean percentage of $\mathrm{HR}_{\max }$ of $93 \pm 2 \%$ but they used percentage of $\mathrm{HR}_{\max }$ and not percentage of $\mathrm{HR}_{\mathrm{res}}$. In the present study the average percentage of $\mathrm{HR}_{\max }$ amounted to $81 \pm 2 \%$ (race $\mathrm{Z}$ ) and to $82 \pm 4 \%$ (race A). This is less than that reported by Duc et al. (2011). The difference is likely due to the race being much shorter (mean time of the 'Trace Catalane': $1 \mathrm{~h} 41 \mathrm{~min} \pm 11 \mathrm{~min}$ ).

In our study the distribution of time spent in the HR zones, below and above $\mathrm{vt}_{2}$ was quite heterogeneous: some athletes spent more than half of race time above $90 \%$ of $\mathrm{HR}_{\text {res }}$ whereas others spent more than $2 / 3$ of race time below $70 \%$ of $\mathrm{HR}_{\text {res}}$; some athletes spent no time above the ventilatory threshold whereas other spent three quarters of the race time above this value. The likely reason is that 'La Patrouille des Glaciers' is a team event and that the three athletes of a patrol must stay together. If a team is made up of athletes of different performance capacity this will lead to intra-team differences for HR. This makes inter-individual comparisons difficult but reflects the reality of most multi-hour ski mountaineering races that generally are team events. This team effect may also at least partly explain our finding of a modest influence of $V_{2}$ max $u$ upon race performance.

\section{Food and drink supply}

The high EE we found should be associated with important food and drink intake during the race to at least partly balance it. That is even truer in altitude where substrate utilization is modified. More blood glucose is used at rest and during exercise (Brooks et al. 1992). The high blood glucose utilization has no sparing effect on muscle glycogen; consequently, carbohydrate need is increased and exogenous carbohydrate consumption during the race is likely of great importance.

The mean energy intake during race A from food and liquids was only $4.4 \pm 1.3$ or $7.1 \pm 1.8 \mathrm{MJ}$ with pre-race breakfast included. This implied an average energy deficit at the finish of the race of $18.2 \pm 2.9 \mathrm{MJ}$, respectively, $13.4 \pm 3.6$ MJ. The recommendations of the ACSM for endurance sports are $0.7 \mathrm{~g}$ carbohydrates $\cdot \mathrm{kg}^{-1} \mathrm{~h}^{-1}$, which in our study amounted to an average value of $5.1 \pm 0.9 \mathrm{~kJ}$, and the recommendations were therefore not met by $14 \%$. But an energy deficit cannot be avoided during such races because the access to and capacity to eat and process food is limited (Diamond 1991). Apart from the practical difficulties of eating while being engaged in sports, a physiological limiting step is the capacity of absorption of the small intestine. The sodium dependant transporters 
of glucose (SGLT1) become saturated at a carbohydrate intake around $7 \mathrm{~g} \times \mathrm{kg}^{-1} \mathrm{~h}^{-1}$, the rate recommended by the ACSM. Nevertheless, even if all athletes had followed the recommendation, the deficit would have been $15.8 \mathrm{MJ}$ (12.4 MJ, pre-race breakfast included) (Rodriguez et al. 2009).

The subjects who finished the race A lost $1.5 \pm 1.1 \mathrm{~kg}$, i.e., $2 \pm 1 \%$ of their body mass. The guidelines (Jeukendrup 2011) recommend that endurance athletes should attempt to minimize dehydration by limiting body mass loss through sweating to not more than $2-3 \%$ of body mass. Thus, our athletes followed the recommendations for rehydration. Knechtle et al. (2012) reported similar weight loss, $1.9 \pm 1.4 \mathrm{~kg}$, during a $100 \mathrm{~km}$ ultra-marathon. Kruseman et al. (2005) reported a weight loss of $4.5 \pm 1.5 \mathrm{~kg}$ during a $7 \mathrm{~h} 3 \mathrm{~min} \pm 1 \mathrm{~h} 17$ min mountain running marathon. The longer duration and the fact that the race took place in summer with higher temperatures can explain the higher losses than observed in our study.

The sweat loss and water need depend on the evaporation required to maintain heat balance at any given core temperature and on the maximal evaporative capacity of the environment. The first depends on skin and core temperature and metabolic rate, and the second on clothing, environmental temperature, wind and humidity (Gonzalez et al. 2009). For a winter mountain race like 'La Patrouille des Glaciers' the low temperatures and air dryness bring the sweat loss down compared to other events of same duration in warmer and more humid conditions. On race day, the air was dry and there was a lot of wind at altitude. In altitude diuresis is increased and thirst impaired (Kayser 1994; Meyer et al. 2011). Furthermore, respiratory water loss is greater in altitude than at sea level due to increased ventilation and low air humidity. Respiratory water loss can be as high as $1.90 \mathrm{~L} \mathrm{day}^{-1}$ for men (Butterfield et al. 1992) and $0.85 \mathrm{~L} \mathrm{day}^{-1}$ for women (Mawson et al. 2000).

For races of such long duration, loss of body mass is not only function of dehydration but also due to use of energy substrate. At the end of a long race like 'La Patrouille des Glaciers', glycogen stores are mostly depleted, whereas they are generally full at the start since most athletes use nutritional strategies stocking up on glycogen reserve prior to major competitions. Given that glycogen is stored with 3-4 parts of water per glucose unit, the oxidation of $500 \mathrm{~g}$ of glycogen $(8,368 \mathrm{~kJ})$ would have involved $>1.5 \mathrm{~kg}$ weight loss. So it seems that our athletes were not much dehydrated and it follows that their drinking habits can be considered appropriate.

\section{Correlates of performance}

Like for other endurance sports, we found that age (Lara et al. 2014), body and gear mass (Tosi et al. 2009), $V \mathrm{O}_{2 \max }$ and EC correlated with performance in multi-hour ski mountaineering racing. That was expected, and confirms that the great importance given by athletes to reduce the mass of their equipment is at least partly justified. However, body mass cannot be neglected. Mass is especially important for sports with ascensions, like ski mountaineering, because a great part of the energy consumption is used to overcome gravity (Ardigo et al. 2003; Saibene and Minetti 2003). The part of total energy consumption used against gravity (Potential energy/EE) were, respectively, $22 \pm 3$ and $18 \pm 3 \%$ for race $\mathrm{Z}$ and $\mathrm{A}$.

The influence of the EC showed that it is important to optimize ski mountaineering technique by specifically training this type of locomotion. Training and experience influence EC (Beneke and Hutler 2005). The more the athlete trains for a sport, the more economical he may become.

The fraction of the time that the athletes spent for the way up and for the way down of the $\mathrm{Z}$ race was calculated. There was no correlation between the fraction of the time spent for the way up and performance. In fact, this fraction did not vary much from one person to another and shows that skiers who perform better on the way up also do better on the way down.

\section{Limitations}

Sea level aerobic capacity was measured $8-12$ weeks before the race and changes in that period cannot be excluded. However, the individual altitude corrected $\mathrm{HR}-\mathrm{VO}_{2}$ relationships were obtained more close (2-4 weeks) to the start of the race. Since there were similar HR- $V \mathrm{O}_{2}$ relationships between the two tests at submaximal stages, we are confident about the use of the HR- $V \mathrm{O}_{2}$ relationship to transform $\mathrm{HR}$ on race day into $\mathrm{VO}_{2}$.

Calorimetry would have been the most accurate method to measure EE and EC. Nevertheless the use of calorimetry for field activity is unfeasible. For indirect calorimetry, $V \mathrm{O}_{2}$ must be measured, which implies that participants wear a mask and a bulky metabolic testing system. To limit interference with performance it is more practical to measure HR with a thoracic belt and a watch, associating it with laboratory measured individual $\mathrm{HR}-V \mathrm{O}_{2}$ relationships, taking into account the effect of altitude, since HR- $V \mathrm{O}_{2}$ relationships shift with increasing altitude. This method seemed to give us similar values compared with other studies.

The HR-altitude- $-\mathrm{O}_{2}$ relationship was determined on a motorized treadmill with skis, skins, poles, etc., to be then used to interpret HR collected on snow, assuming that this relationship is similar on treadmill and on snow. This seems a reasonable assumption since Tosi et al. (2010) found similar EC values on a treadmill and on snow (2009). The main difference is that Tosi et al. used roller skis while normal 
skis with skins were used in the present study. With roller skis on a treadmill the friction is perhaps lower than with skins on snow whereas with skis and skins on treadmill the friction may be higher than on snow.

Several factors might have influenced HR during the race independently from oxygen consumption, such as the excitement of the race. In addition, cardiac drift (EsteveLanao et al. 2008) during long-duration exercise may also have influenced HR during the race. For a same intensity or speed HR increases with time. So an increasing HR does not always means an increasing speed, like a constant HR does not always means a constant speed or intensity. The drift already begins after $10 \mathrm{~min}$ and is especially important for multi-hour exercises. We can estimate that the drift can increase HR by about $10 \mathrm{bpm}$ for a given intensity between start and finish of the race (about $5 \mathrm{~h}$ ) (Gimenez et al. 2013). The limited dehydration in our subjects and the relatively low air temperature probably limited the extent of cardiovascular drift (Montain and Coyle 1992). During the downhill sections eccentric muscular activity may also have lead to an exaggerated HR response (Turnbull et al. 2009).

The race cancellations are clearly the most important limitation of this study. We lost more than half of the subjects. In addition, the remaining subjects became, by chance, less representative of the general population of participants. Almost all women could not start; the majority of our youngest and oldest subjects were also eliminated. But overall as many slow as fast subjects were lost. The effect of sex could thus not be evaluated for race A because there were no women who reached the finish, while the effect of sex in race $\mathrm{Z}$ is influenced by the fact that there was only one women's patrol and this team was very fast. Moreover, age was not any more evenly distributed for race A and the correlation between age and performance is therefore difficult to evaluate. Finally, the interruption of the race $\mathrm{Z}$ halfway made calculation of energy expenditure for the full race $\mathrm{Z}$ impossible and we could therefore only estimate it, while the exercise intensity chosen by the participants was likely lower than if the participants had known about the interruption.

\section{Perspectives and conclusions}

Multi-hour ski mountaineering racing requires a lot of energy (about $20 \mathrm{MJ}$ for $5 \mathrm{~h} 30 \mathrm{~min}$ on average). This very high requirement is not balanced by energy intake in parallel, and the majority of the athletes do not fulfil the recommendations of ACSM for energy intake during endurance sports. On the other hand, dehydration may not be a major problem for this type of race since weight loss remains limited. The dry and cold high mountain environment in winter conditions likely contributes to this. Exercise intensity is high, but heterogeneous because performance capacity between members in a team can vary. Age, low body and racing gear mass, high $V \mathrm{O}_{2 \max }$ and low energy cost are significantly correlated with performance. Accordingly, ski mountaineering athletes should be advised to increase food intake during racing, adapt exercise intensity during training according to expected race intensity and beware of the importance of body and gear mass for performance.

Acknowledgments This study was supported by a grant from the Swiss federal office for sports. We thank Philippe Vuistiner, Vincent Favre, Joachim Staub, Olivier Dériaz and the team of the Swiss Olympic Medical Center of Sion for their excellent technical help. We are also very grateful to the subjects for their precious time in participating in the study.

Conflict of interest There are no conflicts of interests.

\section{References}

Achten J, Jeukendrup AE (2003) Heart rate monitoring: applications and limitations. Sports Med 33:517-538

Ardigo LP, Saibene F, Minetti AE (2003) The optimal locomotion on gradients: walking, running or cycling? Eur J Appl Physiol 90:365-371. doi:10.1007/s00421-003-0882-7

Beneke R, Hutler M (2005) The effect of training on running economy and performance in recreational athletes. Med Sci Sports Exerc 37:1794-1799

Black AE, Coward WA, Cole TJ, Prentice AM (1996) Human energy expenditure in affluent societies: an analysis of 574 doublylabelled water measurements. Eur J Clin Nutr 50:72-92

Brooks GA et al (1992) Muscle accounts for glucose disposal but not blood lactate appearance during exercise after acclimatization to 4,300 m. J Appl Physiol (1985) 72:2435-2445

Butterfield GE, Gates J, Fleming S, Brooks GA, Sutton JR, Reeves JT (1992) Increased energy intake minimizes weight loss in men at high altitude. J Appl Physiol (1985) 72:1741-1748

di Prampero PE (1986) The energy cost of human locomotion on land and in water. Int J Sports Med 7:55-72. doi:10.105 5/s-2008-1025736

Diamond J (1991) Evolutionary design of intestinal nutrient: enough but not too much. News Physiol Sci 6(92):96

Diaz E et al (2010) Cell damage, antioxidant status, and cortisol levels related to nutrition in ski mountaineering during a two-day race. J Sports Sci Med 9:338-346

Duc S, Cassirame J, Durand F (2011) Physiology of ski mountaineering racing. Int $\mathrm{J}$ Sports Med 32:856-863. doi:10.105 5/s-0031-1279721

Esteve-Lanao J, Lucia A, deKoning JJ, Foster C (2008) How do humans control physiological strain during strenuous endurance exercise? PLoS One 3:e2943. doi:10.1371/journal.pone.0002943

Gatterer H, Schenk K, Wille M, Raschner C, Faulhaber M, Ferrari M, Burtscher M (2013) Race performance and exercise intensity of male amateur mountain runners during a multistage mountain marathon competition are not dependent on muscle strength loss or cardiorespiratory fitness. J Strength Cond Res 27:2149-2156. doi:10.1519/JSC.0b013e318279f817

Gimenez P, Kerherve H, Messonnier LA, Feasson L, Millet GY (2013) Changes in the energy cost of running during a 24-h treadmill exercise. Med Sci Sports Exerc 45:1807-1813. doi:10.1249/ MSS.0b013e318292c0ec 
Gonzalez RR, Cheuvront SN, Montain SJ, Goodman DA, Blanchard LA, Berglund LG, Sawka MN (2009) Expanded prediction equations of human sweat loss and water needs. J Appl Physiol (1985) 107:379-388. doi:10.1152/japplphysiol.00089.2009

Haddad M, Chaouachi A, del Wong P, Castagna C, Hue O, Impellizzeri FM, Chamari K (2014) Influence of exercise intensity and duration on perceived exertion in adolescent Taekwondo athletes. Eur J Sport Sci 14(Suppl 1):S275-S281. doi:10.1080/17461391. 2012.691115

Jeukendrup AE (2011) Nutrition for endurance sports: marathon, triathlon, and road cycling. J Sports Sci 29(Suppl 1):S91-S99. doi:1 0.1080/02640414.2011.610348

Kayser B (1994) Nutrition and energetics of exercise at altitude. Theory and possible practical implications. Sports Med 17:309-323

Keytel LR, Goedecke JH, Noakes TD, Hiiloskorpi H, Laukkanen R, van der Merwe L, Lambert EV (2005) Prediction of energy expenditure from heart rate monitoring during submaximal exercise. J Sports Sci 23:289-297. doi:10.1080/02640410470001730089

Kimber NE, Ross JJ, Mason SL, Speedy DB (2002) Energy balance during an ironman triathlon in male and female triathletes. Int $\mathbf{J}$ Sport Nutr Exerc Metab 12:47-62

Knechtle B, Knechtle P, Wirth A, Alexander Rüst C, Rosemann T (2012) A faster running speed is associated with a greater body weight loss in 100-km ultra-marathoners. J Sports Sci 30:11311140. doi:10.1080/02640414.2012.692479

Kruseman M, Bucher S, Bovard M, Kayser B, Bovier PA (2005) Nutrient intake and performance during a mountain marathon: an observational study. Eur J Appl Physiol 94:151-157. doi:10.1007/ s00421-004-1234-y

Lara B, Salinero JJ, Del Coso J (2014) The relationship between age and running time in elite marathoners is U-shaped. Age (Dordr) 36(2):1003-1008. doi:10.1007/s11357-013-9614-Z

Mawson JT, Braun B, Rock PB, Moore LG, Mazzeo R, Butterfield GE (2000) Women at altitude: energy requirement at 4,300 m. J Appl Physiol (1985) 88:272-281

Meyer NL, Manore MM, Helle C (2011) Nutrition for winter sports. J Sports Sci 29(Suppl 1):S127-S136. doi:10.1080/02640414.201 1.574721

Minetti AE (1995) Optimum gradient of mountain paths. J Appl Physiol 79:1698-1703
Montain SJ, Coyle EF (1992) Influence of graded dehydration on hyperthermia and cardiovascular drift during exercise. J Appl Physiol (1985) 73:1340-1350

Richalet JP (2012) Altitude and the cardiovascular system. Presse Med 41:638-643. doi:10.1016/j.lpm.2012.02.003

Rodriguez NR, Di Marco NM, Langley S (2009) American College of Sports Medicine position stand. Nutrition and athletic performance. Med Sci Sports Exerc 41:709-731. doi:10.1249/MSS.0b013e31890eb86

Saibene F, Minetti AE (2003) Biomechanical and physiological aspects of legged locomotion in humans. Eur J Appl Physiol 88:297-316. doi:10.1007/s00421-002-0654-9

Saris WH, van Erp-Baart MA, Brouns F, Westerterp KR, ten Hoor F (1989) Study on food intake and energy expenditure during extreme sustained exercise: the Tour de France. Int J Sports Med 10(Suppl 1):S26-S31. doi:10.1055/s-2007-1024951

Tartaruga MP, Mota CB, Peyre-Tartaruga LA, Brisswalter J (2013) Scale Model on performance prediction in recreational and elite endurance runners. Int J Sports Physiol Perform 9(4):650-655

Tosi P, Leonardi A, Schena F (2009) The energy cost of ski mountaineering: effects of speed and ankle loading. J Sports Med Phys Fit 49:25-29

Tosi P, Leonardi A, Zerbini L, Rosponi A, Schena F (2010) Energy cost and efficiency of ski mountaineering. A laboratory study $\mathrm{J}$ Sports Med Phys Fitness 50:400-406 (R40103056)

Turnbull JR, Kilding AE, Keogh JWL (2009) Physiology of alpine skiing. Scand J Med Sci Sports 19(2):146-155. doi:10.1111/j.1600-0838.2009.00901.x

Vernillo G, Agnello L, Drake A, Fiorella P, Piacentini MF, La Torre A (2012) Cardiovascular responses during an indoor race walking competition. J Sports Med Phys Fit 52:589-595

Wasserman K, McIlroy MB (1964) Detecting the threshold of anaerobic metabolism in cardiac patients during exercise. Am J Cardiol 14:844-852

Westerterp KR, Meijer GA, Janssen EM, Saris WH, Ten Hoor F (1992) Long-term effect of physical activity on energy balance and body composition. Br J Nutr 68:21-30

Wicks JR, Oldridge NB, Nielsen LK, Vickers CE (2011) HR index-a simple method for the prediction of oxygen uptake. Med Sci Sports Exerc 43:2005-2012. doi:10.1249/MSS.0b013e318217276e 